\title{
Ética e educação: uma revisão da literatura educacional de 1990 a 2003
}

\author{
Yves de La Taille \\ Lucimara Silva de Souza \\ Letícia Vizioli
}

Universidade de São Paulo

\section{Resumo}

Trata-se uma análise quantitativa e qualitativa de dissertações, teses e artigos publicados de 1990 a 2003, que versam sobre a relação entre ética e educação e temas relacionados (disciplina, autoridade, limites, violência na escola). Os critérios empregados para a análise foram: 1) a quantidade da produção; 2) definições de ética e moral empregadas; 3) referenciais teóricos adotados e presença de pesquisa empírica; 4) adoção, ou não, de postura crítica em relação à sociedade e à escola; 5) presença de propostas pedagógicas de formação ética dos alunos; e 6) referências, ou não, ao documento Ética dos Parâmetros Curriculares Nacionais. As principais conclusão foram: 1) o tema ética e educação tem sido, nos últimos anos, objeto de um número maior de publicações, embora esse número ainda permaneça pequeno; 2) ética é, quase sempre, referida a prescrições derivadas do reconhecimento de direitos e deveres, portanto quase não se encontram referências ao tema clássico da "vida boa"; 3) Filosofia, sociologia e psicologia moral são os referenciais teóricos que mais inspiram as reflexões; 4) há pouca pesquisa empírica, a maioria dos textos são especulativos e críticos; 5) praticamente não se encontram propostas pedagógicas escolares de formação ética dos alunos, nem referência aos Parâmetros Curriculares Nacionais.

\section{Palavras-chave}

Ética - Moral - Educação. 


\title{
Ethics and education: a survey of the educational literature from 1990 to 2003
}

Yves de La Taille

Lucimara Silva de Souza

Letícia Vizioli

Universidade de São Paulo

\begin{abstract}
The work presents a quantitative and qualitative analysis of dissertations, theses, and articles published from 1990 to 2003 on the relation between ethics and education, and associated issues (discipline, authority, limits, violence at school). The criteria employed in the analysis were: 1) the amount of academic production; 2) definitions of ethics and moral used; 3) theoretical frameworks adopted and presence of empirical research; 4) adoption or otherwise of critical stance in relation to society and to school; 5) presence of pedagogical proposals for the ethical education of students; and 6) reference or otherwise to the document Ética dos Parâmetros Curriculares Nacionais (Ethics of the National Curriculum Parameters). The main conclusions were: 1) the number of publications on the theme of ethics and education has increased in the last years, although the amount remains small; 2) ethics is, almost invariably, related to directions derived from the recognition of rights and duties, therefore references to the classical theme of the "good life" are virtually absent; 3) philosophy, sociology and moral psychology are the theoretical frameworks that most inspire the reflections; 4) there is little empirical research; most texts are speculative and critical; 5) pedagogical proposals for the ethical education of students are practically absent, as are references to the National Curriculum Parameters.
\end{abstract}

\section{Keywords}

Ethics - Moral - Education. 
É notório o quanto a palavra "ética" tem transitado nas mais diversas esferas da vida contemporânea. Não raros são os congressos científicos que reservam um espaço para discutir as relações entre a ética e diversas disciplinas. $\mathrm{Na}$ academia, está na ordem do dia a constituição de Comissões ou Comitês de Ética, funil crítico pelo qual, na visão de alguns, todos os projetos de pesquisa que envolvem seres humanos e animais deveriam obrigatoriamente passar. Algumas revistas científicas começam até a recusar-se a publicar relatos de pesquisa que não tenham sido aprovadas pelas referidas comissões. Se as discussões sobre "ética e pesquisa" costumam ser travadas intra muros, outras estão praticamente na rua, como, por exemplo, a "ética na política", a "bioética" e a "ética na mídia". Note-se que um número crescente de empresas debruçam-se sobre a "sua" ética, celebrando o que Gilles lipovetsky chama de "noivado entre a ética e o business" (1992, p. 313). Em suma, impossivel, hoje, alguém não apresentar-se como "pessoa ética". É a palavra mágica da respeitabilidade.

Paradoxalmente, talvez nunca as queixas sobre o comportamento humano tenham sido tão freqüentes e radicais. Algumas delas: esferas do poder político corroídas pela corrupção; o crime organizado cresce a olhos vistos e estende sua influência; a violência urbana aumenta e toma ares de barbárie; as incivilidades envenenam as relações pessoais; a desconfiança mútua esgarça o tecido social; o terrorismo redesenha a ordem mundial. E há tantas outras mais. A despeito de tantas reflexões e comissões de ética, o mundo parece pouco ético. Aliás, se o fosse, não seriam necessários tantos dispositivos de controle do comportamento dos cidadãos, que vão das câmeras e radares ao patrulhamento do "politicamente correto". Mas talvez não se trate de um paradoxo real, mas simplesmente do efeito de uma situação concreta: se tanto se fala em ética, é que se sofre de um mal-estar ético. As coisas não vão bem e buscam-se explicações e soluções. Note-se que tem aumentado o número de publicações sobre ética, ou temas relacionados, como as virtudes, a sabedoria, a felicidade. Se as discussões contemporâneas certamente refletem um progresso da reflexão humanista, também parecem traduzir um sintoma de crise social de valores.

$\mathrm{E}$, neste cenário, como fica a Educação? Ela também está envolvida nesse debate? Estaria implementando programas de formação ética dos alunos? Ou está alheia a esta "febre moral" que mobiliza tantas pessoas e instituições?

0 objetivo deste artigo é começar a responder a essas perguntas por intermédio de uma análise, não do que efetivamente se faz nas salas de aula, mas sim das produções acadêmicas brasileiras a respeito do tema em tela. Fizemos uma revisão de dissertações, teses e artigos que versaram sobre ética e educação (e temas relacionados - ver método) de 1990 a 2003. Esta revisão logo evidenciou uma ampla gama de problemáticas e abordagens. Dito de outra maneira, o tema ética e educação, diferentemente de outros (como alfabetização ou ensino de matemática), não inspirou, pelo menos até agora, questões centrais, que se encontrariam em praticamente todas as publicações, não trouxe polêmicas precisas em torno das quais os autores se posicionariam. Logo, para organizar nossa apresentação, tivemos de, nós mesmos, eleger critérios que reputamos relevantes para apresentar nossos dados e análises. Eis os critérios que elegemos e a partir dos quais organizamos nosso artigo:

1. Quantidade da produção.

2. Presença, ou não, de uma definição do que seja ética (e, ou moral).

3. Tipo de abordagem teórica empregada.

4. Presença, ou não, de uma perspectiva crítica da sociedade e escola contemporâneas.

5. Presença, ou não, de propostas educacionais para a formação ética dos alunos.

6. Referência, ou não, ao documento Ética dos Parâmetros Curriculares Nacionais (PCNS). 
No decorrer do texto, defenderemos a importância destes critérios para a avaliação do "estado da arte" da reflexão sobre a relação entre ética e educação. Mas, antes de mais nada, vamos explicitar o método que empregamos para levantar o material analisado.

\section{Método}

Por intermédio de uma busca feita na internet, fizemos um levantamento de dissertações, teses e artigos produzidos no Brasil de 1990 até o primeiro semestre de 2003. Os artigos publicados em revistas brasileiras escritos por pesquisadores estrangeiros (e, portanto, traduzidos) não foram computados. ${ }^{1}$

As bases de dados utilizadas de teses e dissertações foram:

$$
\begin{aligned}
& \text { - Dedalus } \\
& \text { - Capes } \\
& \text { - Unicamp } \\
& \text { - Unesp } \\
& \text { - UFSCAR } \\
& \text { - PUC-RS } \\
& \text { - PUC-SP } \\
& \text { - Mackenzie } \\
& \text { - UFRGS } \\
& \text { - UFPB } \\
& \text { - IBICT - BDTD (Biblioteca Digital de Teses } \\
& \text { e Dissertações) } \\
& \text { - ERL - Biológicas } \\
& \text { - ERL - Humanas }
\end{aligned}
$$

As bases de dados utilizadas de artigos foram:

$$
\begin{aligned}
& \text { - SciELO } \\
& \text { - ERL - Biológicas (PsycINFO) } \\
& \text { - ERL - Humanas } \\
& \text { - IBICT - CCN (Catálogo Coletivo Nacional de } \\
& \text { Publicações Seriadas) } \\
& \text { - BIREME/LILACS } \\
& \text { - BIREME/SIDORH } \\
& \text { - BIREME/WHOLIS } \\
& \text { - BIREME/SeCs }
\end{aligned}
$$

\section{- BIREME/CCREPI \\ - BIREME/INDEXPSI \\ - BIREME/SIRPEP}

$\mathrm{Na}$ busca realizada para as teses e dissertações, as categorias de análise (palavraschave) utilizadas foram: educação, ética e moral. Como se sabe (ver Definições de ética), os conceitos de moral e ética são freqüentemente empregados como sinônimos, logo, fazia-se necessário também pesquisar a associação entre moral e educação.

Também estendemos nosso universo pesquisando os seguintes temas: disciplina, indisciplina, autoridade, limites, e violência. Foram fixadas as palavras-chave "moral", "ética" e "educação" fazendo, a partir disso, cruzamentos com os temas relacionados. Damos a este temas o nome de "temas relacionados", e isso por duas razões: uma de ordem teórica, outra de ordem prática. A de ordem teórica: embora não se confundam com e nem se sobreponham às questões estritamente éticas ou morais, temas como disciplina, cidadania, incivilidade, etc., as contemplam, notadamente no que tange a questão do respeito por outrem. A de ordem prática: não raras vezes, são problemas de relacionamento professor/aluno ou aluno/aluno, de indisciplina ou de desobediência a professores que motivam, no meio educacional, preocupações de ordem moral e ética. Por essa razão, achamos importante pesquisarmos os "temas relacionados" e computarmos os trabaIhos cujos autores, eles mesmos, os associaram seja à moral, seja à ética, seja à educação.

Mais duas observações a respeito do levantamento de dissertações e teses: 1) observamos que, ao fazer os cruzamentos das palavraschave para levantamento nos bancos de dados, muitas publicações apareciam repetidas; sendo assim, para um levantamento de tudo que realmente foi publicado, eliminamos os dados repetidos (duplicados), logo, cada tese e dissertação

1. Agradecemos a ajuda fornecida pela biblioteca do Instituto de Psicologia da Universidade de São Paulo em nossa pesquisa eletrônica. 
é contabilizada apenas uma vez; 2) sendo que nos baseamos somente nos resumos apresentados para selecionar os trabalhos que realmente condiziam com o tema proposto, foram eliminadas de nossa amostra as dissertações e teses que não continham resumo expresso nas bases de dados. $^{2}$

$\mathrm{Na}$ busca realizada para os artigos, utilizamos as mesmas categorias de análise (palavras-chave) utilizadas para teses e dissertações. Porém, a partir do que foi levantado nas bases eletrônicas, selecionamos algumas revistas a partir de três critérios: 1) fossem revistas de Educação (certamente há artigos sobre ética e educação em revistas de outras áreas Psicologia, por exemplo - mas pesquisá-las levaria a ampliar demasiadamente nosso universo e inviabilizar nossa pesquisa); 2) tivessem pareceristas que julgam os trabalhos propostos para publicação; 3) contivessem resumos dos artigos. Um outro critério, de ordem estritamente pragmática, foi empregado: a facilidade e, sobretudo, a rapidez de ter em mãos os artigos selecionados. Baseados nestes critérios, procuramos os exemplares presentes nas bibliotecas da Universidade de São Paulo e selecionamos somente os artigos que realmente condiziam com a temática proposta.
As revistas selecionadas em nossa busca foram:

- Cadernos de Pesquisa da Fundação Carlos Chagas;

- Doxa - Revista Paulista de Psicologia e Educação;

- Educação e Pesquisa (Feusp);

- Revista da Faculdade de Educação;

- Revista Brasileira de Educação;

- Revista Brasileira de Estudos Pedagógicos.

A lista dos artigos selecionados encontram-se no final deste trabalho.

Para finalizar nossa explanação sobre o método, falta dizer que lemos na íntegra apenas os artigos acima citados. Das dissertações e das teses, foram lidos apenas os resumos, pois seria impossivel ter acesso a todos esses trabalhos de pós-graduação, espalhados em diversas bibliotecas do Brasil. É por essa razão que, com exceção do segundo item (Aspectos Quantitativos), somente analisamos os artigos.

2. É interessante notar que um número considerável de publicações continham o tema Ética relacionado à medicina (bioética), à formação profissional (ética profissional), à área judicial e à pratica esportiva. Porém, as mesmas foram desconsideradas por não condizerem com os objetivos do presente texto.

Figura 1: Total de dissertações e teses produzidas de 1990 a 2003.

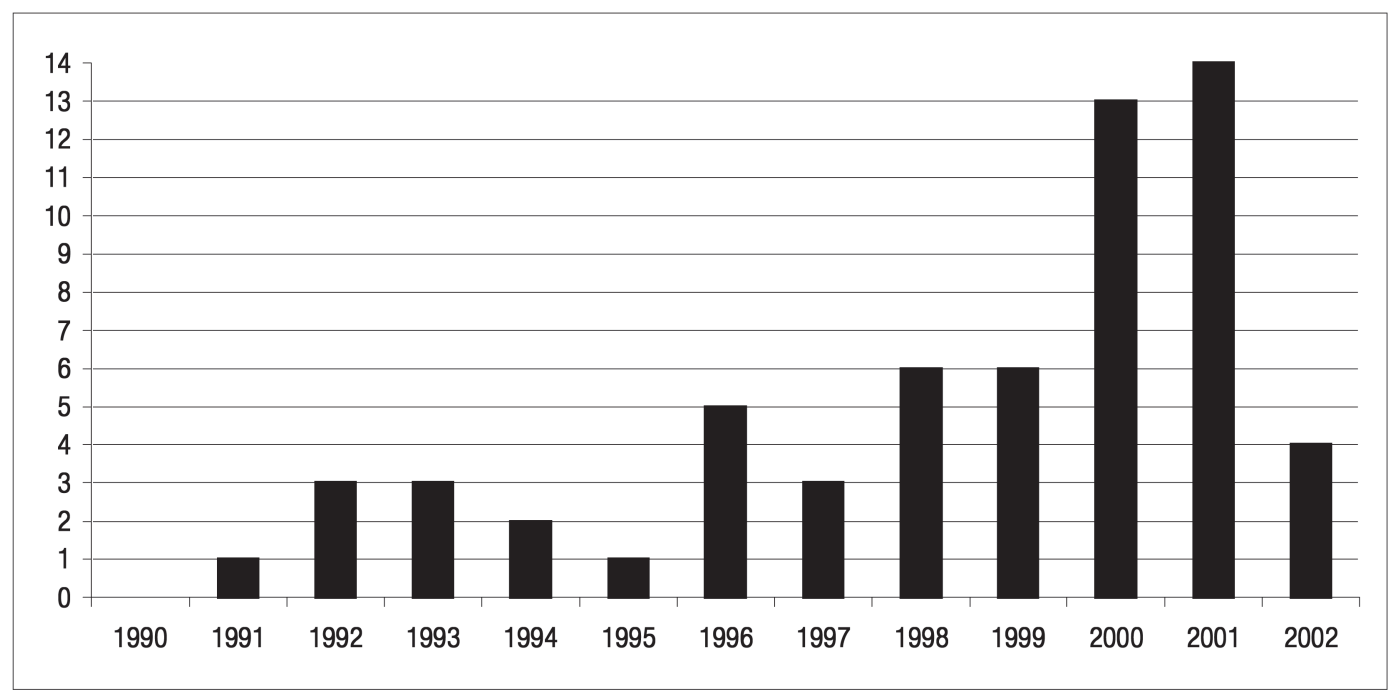


É claro que seria muito rico ler por inteiro todas as dissertações, teses e os artigos publicados em diversas revistas às quais não tivemos acesso. Estamos conscientes das limitações de nossa pesquisa, mas esperamos que inspire outras, notadamente realizadas em diferentes regiões do Brasil.

\section{Aspectos quantitativos}

0 volume de dissertações, teses e artigos destinados a analisar a relação ética/educação (ou temas relacionados) é um dado relevante por si só. Eles estão em quantidade apreciável? 0 número de produções tem aumentado no decorrer destes últimos treze anos? Tem diminuído? Há picos? Em poucas palavras: o tema ética tem sido objeto das preocupações dos pesquisadores em educação? Vamos aos dados.

Comecemos por apresentar o número de dissertações e teses produzidas no período pesquisado (Figura 1).

Encontramos 61 trabalhos realizados no contexto da pós-graduação em Educação. Não é um número elevado, pois nem corresponde a cinco trabalhos por ano. Logo, não se pode afirmar que ética e educação seja um tema candente das reflexões educacionais. Note-se, no entanto, que a produção tem paulatinamente aumentado e que a metade dos trabalhos foi produzida de 2000 a 2002 (31 itens): esse fato mostra o crescente interesse pela ética no meio acadêmico educacional, e é coerente com a atual preocupação a respeito das relações sociais e dos valores. Em suma, na virada do século XX para o XXI, pensa-se mais em ética e educação.

Como não empregamos apenas as palavras moral e ética para nosso levantamento, mas também outras como "limites", "violência", etc., é importante verificar como se distribuem os trabalhos encontrados em relação às palavras-chave (Tabela 1).

Discutiremos mais adiante a possível sinonímia dos conceitos de moral e ética. Por
Tabela 1: Total encontrado de teses e dissertações separado pelas palavras-chave (categorias de análise) selecionadas na busca incluindo teses e dissertações repetidas, isto é, que apareceram em mais de um cruzamento diferente.

\begin{tabular}{|l|c|}
\hline \multicolumn{1}{|c|}{ Palavras-chave cruzadas } & \multicolumn{1}{c|}{$\begin{array}{c}\mathbf{N}^{0} \text { de teses e } \\
\text { dissertações }\end{array}$} \\
\hline Ética e moral & 1 \\
\hline Ética e educação & 24 \\
\hline Moral e educação & 17 \\
\hline Autoridade e educação & 11 \\
\hline Disciplina e educação & 9 \\
\hline Indisciplina e educação & 2 \\
\hline Limite e educação & 3 \\
\hline Violência e educação & 12 \\
\hline Total & $\mathbf{7 9}$ \\
\hline
\end{tabular}

enquanto, limitemo-nos a constatar que somadas palavras-chave "moral e educação" e "ética e educação", encontramos 41 referências, ou seja, um pouco mais da metade dos trabalhos pesquisados. Curiosamente, os temas "autoridade", "disciplina/indisciplina" e "violência”, que inspiram números equivalentes entre si de trabalhos, despertaram menos interesse por parte dos pesquisadores. 0 tema "limite", quanto a ele, praticamente não aparece (três referências apenas). Dizemos que é interessante porque, como se sabe, tais temas suscitam, atualmente, grandes preocupações no seio do corpo docente da Educação Infantil, do Ensino Fundamental e do Ensino médio. ${ }^{3}$ Não parece haver, portanto, resposta quantitativa à altura das queixas dos docentes e das discussões que se travam dia a dia nas salas de aula. Esse dado é coerente com outro, que analisaremos na seção Propostas educacionais: poucos textos publicados em revistas especializadas trazem propostas pedagógicas de como, concretamente, trabalhar a moral e a ética no contexto escolar, ou de como enfrentar de forma prática os conflitos que lá surgem incessantemente. Notemos que a parca referência ao tema "limites" pode ser explicada pelo caráter metafórico e, portanto, pouco rigoroso desta palavra; mas que isto

3. Um de nós, que teve várias oportunidades de ministrar palestras em escolas sobre o tema da moral e da ética, tem reparado o quanto, nos debates, não é tanto a formação moral dos alunos que preocupa muitos professores, mas sim problemas concretos de conflitos em sala de aula, chamados de indisciplina e incivilidade. 
Figura 2: Total de artigos publicados de 1990 a 2003.

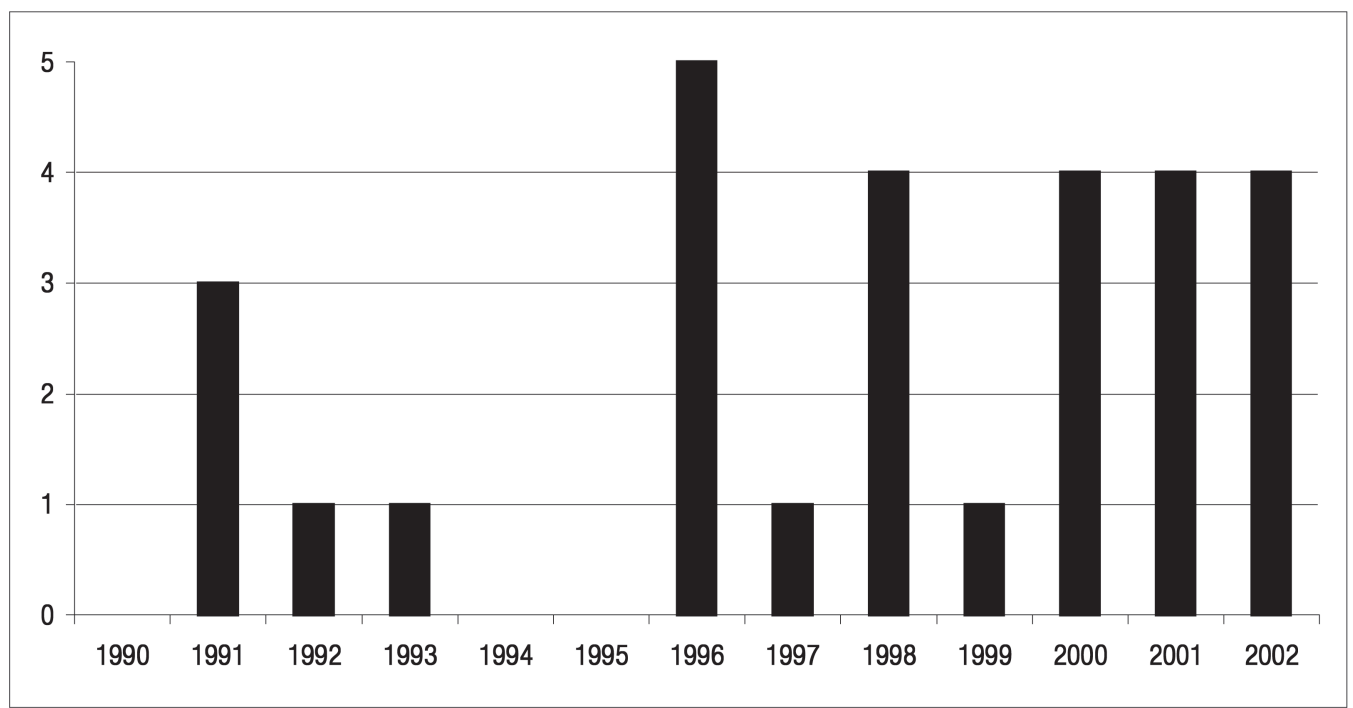

não nos faça perder de vista o grande uso que se faz dela entre os professores e sua freqüente presença nos meios de comunicação.

Vejamos, agora, na Figura 2, a freqüência com o que o tema "ética e educação" (e temas relacionados) é tratado nas revistas especializadas pesquisadas.

Grosso modo, reencontramos aqui a tendência apontada na avaliação dos dados sobre dissertações e teses: o tema em tela não mobiliza muitos pesquisadores (em média, três artigos por ano), mas tem sido objeto de um maior número de reflexões a partir dos últimos anos. Como, no mesmo período, encontramos 61 dissertações e teses, e que, claramente, muitos dos artigos encontrados não foram inspirados em trabalhos de pós-graduação finalizados anteriormente, podemos concluir que muito pouco da produção da pós-graduação sobre ética e educação foi divulgada para além dos muros das universidades. É verdade que talvez o tenham sido em outras revistas (de divulgação ou vulgarização científica, algumas delas por sinal excelentes, mas que, por privilegiarem a clareza e simplicidade do texto, e não seu rigor e aprofundamento reflexivo, empobrecem quase que inevitavelmente o conteúdo) ou livros, mas esta possibilidade não explica a razão da não divulgação em suportes especializados nacionalmente reconhecidos que transitam no meio acadêmico.

Quanto ao detalhe dos temas tratados pelos artigos, vemos na Tabela 2 um quadro estatístico parecido com aquele das dissertações e teses, ou seja, maior destaque para o tema ética/moral e educação.

Daqui para frente, vamos abordar itens de análise qualitativa. Como esta somente é possivel mediante a leitura integral dos trabalhos, vamos nos ater aos 28 artigos publicados nas revistas científicas a que tivemos acesso.

Tabela 2: Total de artigos separado pelas palavras-chave (categorias de análise) selecionadas na busca.

\begin{tabular}{|l|c|}
\hline \multicolumn{1}{|c|}{ Palavras-chave cruzadas } & No de artigos \\
\hline Ética e moral & 0 \\
\hline Ética e educação & 13 \\
\hline Moral e educação & 7 \\
\hline Autoridade e educação & 1 \\
\hline Disciplina e educação & 1 \\
\hline Indisciplina e educação & 2 \\
\hline Limite e educação & 0 \\
\hline Violência e educação & 4 \\
\hline \multicolumn{1}{|c|}{ TOTAL } & $\mathbf{2 8}$ \\
\hline \multicolumn{2}{|c|}{} \\
\hline
\end{tabular}




\section{Definições de ética}

Até o momento, não problematizamos a definição de ética, tampouco a confrontamos ao sentido do conceito de moral. Seria um erro permanecer nesta indefinição, como se ética fosse um conceito com significado inequívoco.

$\mathrm{Na}$ linguagem comum, costumeiramente dá-se à palavra ética a mesma definição que se dá à palavra moral, a saber, referência a um conjunto de princípios e regras cujo respeito é obrigatório e cuja transgressão é, portanto, punida. Quando se diz, por exemplo, que uma pessoa "não tem ética", normalmente significa que ela não pauta suas condutas por regras que, se seguidas, evitariam que alguém fosse, de alguma forma, por ela prejudicado. Uma pessoa sem ética é, neste sentido, uma pessoa imoral. Os códigos de ética das variadas profissões também contêm prescrições, deveres aos quais o profissional deve se submeter. E quando se fala em ética na política, estão em foco condutas consideradas honestas, justas, que não lesam, portanto, o patrimônio público. Por que, então, a atual predileção pela palavra ética em detrimento do emprego da palavra moral? Concordamos com Sptiz quando avalia que "este termo, que adquiriu uma importância cada vez maior, veio aliviar o inextricável embaraço daqueles que desejariam falar de moral sem ousar pronunciar esta palavra" (1995, p. 149). Dito de outra forma, emprega-se em geral a palavra ética para referir-se a normas de conduta, normatização esta também objeto da moral. Porém, a palavra moral "assusta", tem uma conotação autoritária, "moralista”, e é de bom tom evitá-la. Mas não se evita a normatização! No caso da Educação, a triste experiência da disciplina Educação Moral e Cívica ajudou a enterrar a referência à moral. Porém, o emprego comum da palavra ética eqüivale a uma verdadeira exumação.

Todavia, moral e ética não são termos que precisam ser necessariamente empregados como sinônimos. Duas possiveis diferenças de sentido valem a pena ser explicitadas.
Pode-se falar em moral para designar os valores, princípios e regras que, de fato, uma determinada comunidade, ou um determinado indivíduo legitima, e falar em ética para se referir à reflexão sobre tais valores, princípios e regras. A reflexão pode ser filosófica: neste caso discutem-se os fundamentos da moral, seus conteúdos, o valor de suas máximas, etc. Um bom exemplo é a Crítica da razão prática (1985), de Immanuel Kant. Mas a reflexão também pode ser científica, e, neste caso, estudam-se as variáveis sociais, culturais, econômicas, psicológicas do fenômeno humano chamado moral. Assim, pode-se dizer que os trabalhos de Lévy-Bruhl (1971), Freud (1991), Piaget (1932) e Kohlberg (1981, 1984, 1987), entre outros, representam empreendimentos no campo da ética.

A segunda diferença que se faz entre moral e ética não incide sobre o grau de abstração de uma em relação à outra (na definição anterior, a ética estaria em nível superior), mas sim sobre duas problemáticas diferentes, embora certamente indissociáveis. A moral referir-seia à dimensão do dever, enquanto a ética diria respeito à dimensão da felicidade. ComteSponville (In Comte-Sponville; Ferry, 1998) diz que a moral corresponde à pergunta "como devo agir?", e a ética a outra: "que vida quero viver?". Um bom exemplo deste significado dado à ética é o livro de Aristóteles (1965), Ética a Nicômaco, dedicado à reflexão sobre a felicidade e às formas de alcançá-la (cultivo das virtudes). Bem mais perto de nós, Paul Ricoeur também faz a diferença entre moral e ética:

é por convenção que reservarei o termo ética para a procura de uma vida boa e o de moral para a articulação entre esta perspectiva e as normas caracterizadas ao mesmo tempo pela pretensão à universalidade e por um efeito de coação. (1990, p. 200)

Para ele, a perspectiva ética é "a perspectiva da 'vida boa', com outrem e para ou- 
trem, em instituições justas" (Ricoeur, 1990, p. 202).

É claro que, como afirmou Paul Ricoeur, o emprego diferenciado de moral e ética depende de uma convenção. Mas o fato de essas palavras poderem nos remeter a questões distintas (normas, fundamentos, estudos empíricos, vida boa) não deve passar despercebido. Há muita riqueza neste campo de reflexão, notadamente para a educação: trata-se de normatizar as condutas dos alunos? De instruí-los sobre sistemas éticos? De fazê-los refletir sobre as relações humanas? Sobre a felicidade? Sobre as virtudes? 0 tema "ética e educação" pode muito bem referir-se a essas perguntas e a outras ainda.

Vamos então analisar se, nos textos escolhidos, encontram-se definições de ética (ou moral) e, em caso de reposta afirmativa, quais.

0 primeiro dado a ser apontado é que apenas nove artigos $(32,14 \%)$ dedicam-se com maior precisão a definir ética (ou moral), enquanto os dezoito restantes $(67,86 \%)$ não o fazem. ${ }^{4}$ É preciso salientar que muitos deles não trazem uma discussão conceitual simplesmente porque seu tema central é outro, como, por exemplo, violência, autoridade, a obrigatoriedade do ensino segundo os alunos, democracia na escola, etc. Logo, a alta porcentagem de ausência da referida definição não deve ser atribuída a uma ingenuidade teórica, mas sim a opções discursivas. Mas o fato é que, na prática, há pouca problematização conceitual sobre o tema.

O segundo dado a ser mostrado incide sobre as definições encontradas. Os textos de Oliveira (1996); Canen; Franco (2000) problematizam, com o apoio de vários autores, a definição de ética, notadamente no que tange ao caráter universal, ou não, de seus preceitos. Subjaz à discussão apresentada nestes dois textos a ética pensada como normativa, portanto, como conjunto de deveres. Portanto, as questões da reflexão sobre o fenômeno moral, a referência a virtudes e à busca da felicidade estão ausentes. Nos texto de Menin (2002), Bellini; Ruiz (1997), La Taille; Flor; Fevorini (1991), La Taille et al. (2000), todos de inspiração piagetiana e kohlberguiana, ética também aparece como referente a deveres (notadamente o de justiça), mas é feita uma distinção entre agir (definição possível de moral) e refletir sobre a ação (definição possível de ética). Todavia, as virtudes e a questão da felicidade não aparecem. Somente os textos de La Taille (2000) e La Taille (2001) apontam para o tema das virtudes e, mais timidamente, da felicidade, ou "sentido da vida". Em suma, com duas exceções, pode-se dizer que a ética é pensada como referente a valores dos quais derivam-se deveres (inspirados na justiça e no respeito pela dignidade de outrem). Ela não se confunde com moral do ponto de vista do nível de abstração, mas sim do ponto de vista do tema. Os grandes ausentes são os temas da "vida boa" e também das virtudes. Este fato não deve causar estranheza. Com efeito, a ética moderna centrou-se na questão da norma, dos direitos, dos deveres, da justiça, e isto graças, entre outros fatores, à grande influência de Kant, influência esta que se reencontra na maioria dos pesquisadores em Psicologia Moral, como Piaget (1932), Kohlberg (1981), Turiel (1983) e outros. A primazia dada ao tema dos deveres tem sido atualmente questionada por autores como Tugendhat (1998), Maclntyre (1997), Taylor (1998), Ricoeur (1990), Gilligan (1982), mas esta discussão parece ainda não ter inspirado as reflexões sobre ética e educação. A questão da normatividade permanece central, como, aliás, se verifica no documento Ética do Parâmetros Curriculares Nacionais (1997, 1998), dos quais falaremos mais abaixo.

Para acabar este item, é interessante notar que dos nove artigos que cuidam mas

4. 0 artigo de Cunha (1996), dedicado a uma crítica aos Parâmetros Curriculares Nacionais, também traz uma discussão da ética e dos conteúdos propostos pelo documento do MEC. Todavia, como tal discussão incide prioritariamente na tradução educacional presente nos PCNS, e não sobre uma reflexão axiológica, não incluímos este texto entre aqueles que, de fato, assumem uma definição do que seja ética ou moral. 
carinhosamente da definição de ética e moral, sete usam referências da psicologia moral (ver próximo item para a definição). Este fato também não deve causar estranheza uma vez que a psicologia moral, ramo da psicologia criada no começo do século XX, teve de se debruçar, num primeiro momento, sobre a definição de seu objeto, para, depois, estudá-lo. Isso explica também a predominância da dimensão normativa pois, como já comentado, Kant é o filósofo que mais tem inspirado os pesquisadores nesta área.

\section{Abordagens teóricas}

Vamos agora nos preocupar com os referenciais teóricos empregados, e com uma característica particular dos textos: uns apresentam pesquisa empírica, outros não.

Sabe-se que a ética e a moral são objeto de reflexão de vários ramos das ciências humanas e da filosofia. Esta última nos traz definições e análises desde os filósofos gregos até hoje (para ficar no universo ocidental). Entre as ciências humanas, destacam-se a sociologia (análise das variáveis sociais e culturais) e a psicologia moral (análise das variáveis psíquicas presentes no processo da adesão a valores morais e éticos e na legitimação dos princípios e regras de ação decorrentes). Em ambas as abordagens, há clássicos, como Durkheim (1974) e Weber (1963) para a sociologia, e como Freud (1991), Piaget (1932) e Kohlberg (1981, 1984, 1987) para a psicologia. Não nos parece ser exagerado afirmar que coube à psicologia realizar o maior aprofundamento da questão ética e o maior número de pesquisas, notadamente na área de Psicologia do Desenvolvimento. É por esta razão que existe uma área, já consolidada, que alguns chamam de Psicologia Moral. Pode-se colocar a abordagem psicanalítica nesta área? É discutível. Se, por um lado, a psicanálise freudiana explica o fenômeno moral (superego, ideal de ego, repressão, renúncia), não se pode afirmar, por outro, que a moral e a ética sejam um objeto de suas reflexões e pesquisas mais importantes. Diferentemente de, por exemplo, Kohlberg, que dedicou toda a sua obra à elucidação dos processos mentais que presidem o desenvolvimento moral, Freud e seguidores trataram da moral incidentemente, mais em razão das decorrências do sistema teórico adotado do que como objeto privilegiado de reflexão. E isto também acontece com outras áreas da psicologia: por exemplo, pode-se muito bem fazer referências a Vygotsky, Jung ou Rogers para pensar o fenômeno moral e ético, embora tais pesquisadores não sejam autores de teorias que possam ser classificadas como Psicologia Moral.

lsto posto, é preciso confessar que nem sempre é fácil julgar se um texto é, claramente, inspirado num sistema filosófico, numa teoria psicológica ou sociológica, ou ainda numa perspectiva educacional precisa. Com efeito, muitos empregam vários referenciais, caminham de uns aos outros. Há mais: nem sempre nós conhecíamos todos os autores citados, sendo, às vezes, difícil, portanto, situá-los. Finalmente, deve-se lembrar que alguns intelectuais desafiam classificações clássicas, como é o caso de Foucault (filósofo? sociólogo? historiador? os três juntos?) - no caso dele, resolvemos incluí-lo na sociologia, pois suas análises articulam o sujeito e a cultura). Para resolver essa dificuldade, resolvemos analisar apenas as biografias encontradas, identificar os autores cuja obra, de fato, têm inspirado as reflexões sobre o tema que nos ocupa (podem ser considerados "clássicos", como Foucault, Kant, Piaget, Dewey, etc.) A Tabela 3 traz o que encontramos.

Os dados, que não apontam diferenças no tempo, mostram um certo equilíbrio entre psicologia moral, sociologia e filosofia. Que a categoria "Psicologia Não Moral" (referente às abordagens não estritamente focadas no fenômeno moral e ético) tenha apenas $17,89 \%$ das referências é compreensível. Porém, que as referência de Pedagogia/Educação representem os mesmos 17,89\% deve chamar a atenção, pois apontam para uma quase ausência de 
autores conhecidos ou reconhecidos no universo da educação que tratem da questão ética. Este dado é coerente com outro, que apresentaremos mais adiante, em Propostas Educacionais: a quase inexistência de propostas pedagógicas práticas de formação moral e ética. É, naturalmente, perigoso afirmá-lo de modo taxativo, mas parece ser real o fato de não haver, nos dias de hoje, reflexão genuinamente educacional em torno do tema sobre o qual nos ocupamos aqui.

Vejamos agora o número de artigos que apresentam pesquisa empírica: dez apenas (pouco mais de um terço) E, destes dez, oito são de psicologia moral e dois sobre violência, com referencial essencialmente sociológico. 0 que podemos dizer destes dados? Duas coisas. A primeira: há pouca pesquisa empírica e, no nosso corpus, nenhuma diretamente relacionada ao controle da eficácia de práticas educativas. Este estado de coisas talvez se deva ao parco interesse pelo tema, talvez pelo fato de não haver clareza sobre os problemas escolares que devem ser elucidados, talvez também porque praticamente não há propostas de intervenção junto aos alunos (ver em Propostas Educacionais). 0 segundo aspecto a ser comentado é o fato de as pesquisas empíricas que encontramos situarem-se na área de Psi- cologia Moral e estudos sobre a violência, áreas estas nas quais muitas pesquisas são produzidas. Porém, coerentemente com o escopo destas áreas (por exemplo, Estudo da Evasão Escolar e Delinqüência: Adorno, 1991; Castigo e Humilhação: La Taille et al., 2000; Valores de Professores e Ação Pedagógica: Menin, 2002), as pesquisas podem trazer subsídios para a prática pedagógica, mas não a contemplam diretamente.

Em resumo, dois terços dos artigos pesquisados nasceram de reflexões e análises, não de pesquisas empíricas. Serão tais textos, e os demais, críticos em relação à situação atual e à escola? É tema do próximo item.

\section{Perspectiva crítica da sociedade e escola contemporâneas}

É raro acharmos um livro que trata de ética ou de moral que não contenha críticas seja aos comportamentos humanos em geral, seja à sociedade na qual vive o autor. Esse fato não é surpreendente porque ética e moral falam de ideais de comportamento, de modelos de caráter que, por definição, sempre estão acima das reais possibilidades de cada um. Embora freqüente, a presença de crítica não é

Tabela 3: Referências apresentadas nos artigos.

\begin{tabular}{|c|c|c|c|c|c|}
\hline \multicolumn{7}{|c|}{ Referências apresentadas nos artigos: } \\
\hline Ano de publicação & $\begin{array}{c}\text { Psicologia Não } \\
\text { Moral }\end{array}$ & Psicologia Moral & $\begin{array}{c}\text { Pedagogia/ } \\
\text { Educaçã }\end{array}$ & Filosofia & Sociologia \\
\hline $\mathbf{1 9 9 0}$ & 0 & 0 & 0 & 0 & 0 \\
\hline 1991 & 1 & 1 & 0 & 1 & 1 \\
\hline 1992 & 1 & 1 & 0 & 1 & 1 \\
\hline 1993 & 0 & 0 & 0 & 0 & 1 \\
\hline 1994 & 0 & 0 & 0 & 0 & 0 \\
\hline 1995 & 0 & 0 & 0 & 0 & 0 \\
\hline $\mathbf{1 9 9 6}$ & 0 & 0 & 0 & 2 & 3 \\
\hline $\mathbf{1 9 9 7}$ & 0 & 1 & 0 & 0 & 0 \\
\hline $\mathbf{1 9 9 8}$ & 1 & 0 & 2 & 1 & 2 \\
\hline $\mathbf{1 9 9 9}$ & 1 & 0 & 1 & 1 & 0 \\
\hline $\mathbf{2 0 0 0}$ & 0 & 3 & 0 & 2 & 1 \\
\hline $\mathbf{2 0 0 1}$ & 0 & 2 & 2 & 2 & 1 \\
\hline $\mathbf{2 0 0 2}$ & 1 & 1 & 0 & 2 & 2 \\
\hline TOTAL & $\mathbf{5 = 1 7 , 8 6 \%}$ & $\mathbf{9 = 3 2 , 1 4 \%}$ & $\mathbf{5 = 1 7 , 8 6} \%$ & $\mathbf{1 2}=\mathbf{4 2 , 8 6} \%$ & $\mathbf{1 2 = 4 2 , 8 6 \%}$ \\
\hline
\end{tabular}


necessária. Em se tratando de ética e educação, podem-se muito bem encontrar textos que equacionem a relação entre ambas sem tecer críticas à sociedade contemporânea e à própria educação. Podem-se também encontrar textos que proponham ações pedagógicas. Todavia, como a ética é um instrumento de análise e juízo da sociedade, vale a pena verificar se não é nesta perspectiva crítica que o tema ética e educação tem sido tratado. Os dados mostram que sim: 21 textos sobre 28 (78,47\%) tecem críticas seja à sociedade, seja à escola, seja a ambas. Logo, são poucos os textos nos quais não há crítica, e quase todos têm uma característica que explica sua aparente neutralidade: tratam, de forma histórica e teórica, da relação entre ética e educação. Portanto, não são textos dedicados à análise da escola contemporânea. Como exemplo, temos um texto de Cunha (1996) dedicado a "...: notas sobre Rousseau, Bonald e Saint Simon” (como consta no título), outro de La Taille (2000) dedicado ao equacionamento das virtudes no campo moral.

Quanto aos outros, ou seja, aqueles nos quais encontramos críticas à sociedade ou à escola, esses tratam de questões atuais, como a da problemática construção da autonomia por parte dos alunos (por exemplo, Martins, 2002), o aniquilamento das identidades culturais (Oliveira; Canem; Franco, 2000), à violência que se desenha nas relações interpessoais na sala de aula (por exemplo, Sposito, 2001), a exclusão escolar (Adorno, 1991), a crise da autoridade (Davis; Luna, 1991), a indisciplina e a ética docente (Aquino, 1998), entre outros.

\section{Propostas educacionais}

Acabamos de ver que a recente produção sobre ética e educação adota, de maneira geral, uma perspectiva crítica da sociedade contemporânea. Então, como modificar esta sociedade e qual o papel da educação nesta virtual modificação? Há propostas pedagógicas de educação moral ou formação ética? Há rumos indicados? Ou a crítica esgota-se nela mesma, sem o vislumbre de opções pedagógicas? Ou ainda, encontra-se a afirmação de que a educação nada deve fazer em relação à formação ética de seus alunos?

Para responder a essas perguntas classificamos os textos analisados em quatro categorias: 1) os que nada propõem; 2) os que apresentam propostas de formação ética dos alunos; e 3) os que apontam perspectivas educacionais, rumos a serem seguidos, mas sem propostas precisas. Vamos aos dados: dois artigos apresentam propostas concretas, quatorze sugerem rumos e doze não fazem referência a propostas educacionais

0 dado primordial a ser apontado é evidentemente este: apenas dois artigos, o de Araújo (2000) - que propõe, para a construção de "personalidades morais", trabalhar os conteúdos escolares, a metodologia das aulas, a natureza das relações interpessoais, os valores, a auto-estima e o auto-conhecimento - e o de Aquino (1998) - que apresenta cinco regras do trabalho docente para se trabalhar a questão da indisciplina: a compreensão do aluno-problema como porta-voz das relações estabelecidas em sala de aula; a des-idealização do perfil do aluno; a fidelidade ao contrato pedagógico; a experimentação de novas estratégias de trabalho; e a presença da competência e do prazer como valores básicos - apresentam propostas educacionais com relação à formação ética. Se fôssemos mais rigorosos e exigíssemos detalhes de como atuar em sala de aula, nem mesmo esses dois artigos poderiam ser computados. Porém, diante dos rumos educacionais por demais gerais que muitos artigos apresentam, podemos destacar estes dois trabalhos que, pelo menos, concretizam minimamente os princípios a serem seguidos para a formação do aluno.

Certamente, dois artigos sobre 28, num período de treze anos, é muito pouco. É verdade que quatorze outros textos apontam o que chamamos de "rumos". Mas é preciso lembrar que doze simplesmente nada propõem e nada apontam. É claro que tal ausência se deve aos 
objetivos desses textos (análises históricas, sociológicas ou filosóficas). Todavia, o fato está aí: na discussão sobre ética e educação, a prática é a grande ausente. Em outras palavras, percebemos que, baseando-nos em nossa revisão, encontrar formas didáticas de formação moral e ética não é uma preocupação da educação! Discute-se bastante, propõe-se muito pouco. Este dado é digno de nota uma vez que, por um lado, sabe-se que a sociedade como um todo vive um certo mal-estar moral, e que, por outro, grande número dos artigos arrolados aqui estão numa perspectiva crítica da escola e da sociedade. Dizemos que é digno de nota porque parece que estamos num impasse: a situação é crítica, mas não se sabe o que fazer; há um diagnóstico pessimista, mas não há projeto. Qual, ou quais serão as razões que produziram este cenário? Podemos arrolar algumas hipóteses.

A primeira: não haveria propostas pedagógicas porque a opinião dominante é que não cabe à escola a formação moral e ética dos alunos. Um de nós, que tem tido muitas oportunidades profissionais de dialogar com professores de instituições de ensino públicas e privadas de vários estados do Brasil, tem notado que, com efeito, a tendência dos educadores é culpar as famílias pelos comportamentos julgados desrespeitosos, indisciplinados e violentos dos alunos. Não é dito, explicitamente, que não cabe à escola tratar desses problemas, mas a constante culpabilização dos pais equivale, na prática, a uma desresponsabilização da escola. É como se houvesse uma divisão de tarefas: valores, regras morais, virtudes ficam com a família; português, matemática, geografia, etc., com a escola. Esta implícita repartição das "tarefas” educativas talvez explique, em parte pelo menos, por que praticamente nada se encontra sobre propostas pedagógicas de formação ética. Porém, é preciso sublinhar que, em nossa revisão de literatura, encontramos apenas um texto que se posiciona claramente contra o papel da escola para tal formação. Trata-se do texto de Cunha (1996), dedicado à análise dos
Parâmetros Curriculares Nacionais, no qual se lê: "No presente momento da sociedade brasileira, caracterizada por crônica crise de hegemonia, não é possível encontrar um conteúdo ideológico que possa ser legitimamente assumido pelo ensino público" (p. 70). Note-se que o autor não pensa que a escola não deve preocupar-se em hipótese alguma com a formação ética do aluno (diz que talvez seja possível no futuro), mas ele afirma claramente que não deve fazê-lo hoje. Mas, insistimos, é o único texto no qual encontramos uma posição claramente desfavorável a propostas pedagógicas de formação ética. logo, tudo leva a crer que a ausência de propostas não é devida a uma militância consciente e explícita por parte dos educadores. Procuremos, então, outras hipóteses verossímeis.

Uma segunda hipótese pode ser a que segue: a recente experiência brasileira com a disciplina Educação Moral e Cívica transformou o tema da educação moral em tabu. Dela não se deve falar pois o tema é "perigoso". Não há duvidas de que tanto a imposição da referida disciplina por parte de um regime político ditatorial quanto suas características verbalistas (uma aula específica por semana) jogaram uma grande sombra sobre o tema da educação moral. A experiência com Educação Moral e Cívica é ainda recente e certamente ressoa na memória de quem pensa em levar a seus alunos valores morais e éticos. Todavia, se é verdade que existe um certo tabu em relação ao tema de que estamos tratando neste artigo, tal tabu não nos parece tão forte assim para justificar a atual falta de propostas. Fossem as pessoas realmente convencidas de que a formação moral por parte da escola é tarefa incontornável, alternativas teriam sido rapidamente achadas.

Nossa terceira hipótese é a de que há um certo temor em relação ao próprio tema: moral associa-se facilmente a coação, autoritarismo, moralismo. E falar de ética nada muda pois, como vimos acima, este conceito é empregado para se referir a deveres, ou seja, à limi- 
tação da liberdade de ação. Ora, é justamente tal limitação que é, hoje, temida, fenômeno que faz Lipovetsky referir-se ao crepúsculo do dever (1992). Há ausência de bússolas morais de consenso (como apontado por Cunha, 1996) e provavelmente há pouca disposição de se encontrá-las. Dito de outra maneira, o tema da moral e da ética tanto inquieta e atrai quanto angustia e apavora. Falar nele decorre da inquietação, nada propor decorre do medo. Medo este tanto de se voltar a práticas pedagógicas autoritárias quanto de se aceitar que há deveres morais incontornáveis. 0 clima "pósmoderno" em que vivemos, solo fértil para o relativismo, certamente participa do adiamento de tomadas claras de posição a respeito da formação ética e moral.

Uma última hipótese pode ser simplesmente a seguinte: como há, na prática, poucos empreendimentos escolares de educação moral ou ética, pouco se discute e se escreve a respeito. Todavia, não podemos esquecer que, no Brasil, foi elaborada um proposta de formação ética: aquela dos Parâmetros Curriculares Nacionais.

\section{Parâmetros Curriculares Nacionais}

Em 1997 e 1998 o Ministério da Educação e do Desporto do Brasil publica os Parâmetros Curriculares Nacionais (PCNs), que se destinam ao Ensino Fundamental. Como seu nome indica, não se trata de um "currículo mínimo", nem de uma proposta curricular a ser obrigatoriamente adotada por todos os estabelecimentos de ensino. Trata-se realmente de "parâmetros", ou seja, de diretivas gerais que podem inspirar pedagogicamente as escolas que assim o desejarem. A referida proposta referenda algumas experiências educacionais brasileiras, e também se apóia na reforma curricular espanhola da década de 1990. Não é o caso de resumir aqui os PCNs, mas de lembrar que neles é proposto que as escolas enfrentem a tarefa da formação ética dos alunos.
Com efeito, os PCNs incluem os chamados "temas transversais", entre os quais encontramos o tema Ética (os outros são Saúde, Trabalho e Consumo, Orientação Sexual, Meio Ambiente e Pluralidade Cultural). Em poucas palavras, a transversalidade é uma abordagem didática que reza que os temas acima arrolados sejam estudados de forma articulada com as disciplinas clássicas (Língua Portuguesa, Matemática, etc.), a fim, por um lado, de não sobrecarregar o currículo com horas e mais horas de aula e, por outro, de mostrar ao aluno o quanto tais matérias podem ter relação com a vida cotidiana e serem úteis para o exercício da cidadania.

O tema Ética apresenta uma característica singular em relação aos outros "temas transversais": inspirado em teorias psicológicas construtivistas (com destaque para Piaget e Kohlberg), dá-se grande ênfase à qualidade do convívio escolar, que deve, ele mesmo, estar o mais próximo possível de uma comunidade justa. Falta dizer que, nos PCNs, ética é definida com base na dignidade do ser humano, na justiça, na solidariedade e no diálogo.

Naturalmente, não vem ao caso aqui discutir da qualidade do documento Ética dos PCNs, mas sim de sublinhar o fato de que a ética foi objeto de uma proposta curricular nacional, amplamente divulgada no meio educacional (os meios de comunicação, quanto a eles, praticamente nada noticiaram a respeito). A pergunta que se impõe, portanto, é a de saber se, sim ou não, os PCNs foram objeto de reflexão nos artigos que tratam de ética e educação.

Os dados nos mostram claramente que tal não foi o caso: de 1996 a 2003, apenas seis textos se remetem a eles. Não sabemos o quanto a proposta Ética dos PCNs foi abordada nas dissertações e teses, pois, como dissemos parágrafos acima, não lemos este material. Mas o fato é que, em se tratando de artigos publicados em revistas científicas, a referida proposta curricular brilha pela sua ausência. Falemos um pouco desses textos. 
Dois dele resultaram da publicação de pareceres solicitados pelo MEC antes da publicação dos PCNs (daí serem publicados em 1996). O de Cunha, já citado acima, é essencialmente crítico e aconselha pura e simplesmente que os temas transversais todos sejam retirados da proposta governamental. 0 outro, intitulado "Parecer da ANPEd sobre os Parâmetros Curriculares Nacionais”, aborda vários pontos relacionados aos PCNs como um todo e ao processo de elaboração; em relação aos temas transversais, é manifestada simpatia, mas preocupação com a adequação das propostas (notadamente a do documento Ética) à realidade de grande parte do alunado. Eis a íntegra de uma recomendação feita no parecer: "Reformular a abordagem dos temas transversais, de forma a permitir que seu tratamento seja adaptado às diferentes realidades sociais e culturais dos alunos” (p. 90).

0 texto de Cury (também de 1996) faz uma análise histórica dos currículos no Brasil e de suas dimensões constitucionais e não se atém ao documento Ética. 0 texto de Oliveira; Canen; Franco (2000) trata do tema Pluralidade Cultural e de sua articulação com a ética, focando, como já comentado, a questão da tolerância, do relativismo ou universalismo éticos. Finalmente, os textos de La Taille (2001) e Menin (2002) limitam-se a lembrar que existem os PCNs e sua proposta de formação ética e trazem, para que se possa implementar essa proposta curricular, reflexões e dados da área de Psicologia Moral.

Em suma, nossos dados a respeito das referências ao PCNs são coerentes com aqueles do item anterior, a saber, a quase ausência de textos que trazem uma proposta pedagógica e a também não grande quantidade de artigos em que se apontam "rumos" para a formação ética dos alunos. Infelizmente - é pelo menos esta nossa opinião - os PCNS, cujos temas transversais todos, de uma maneira ou de outra, põem em cena a dimensão da ética na formação escolar, não parecem ter desencadeado uma real discussão sobre ética e educa- ção no seio da academia. Tal ausência certamente se deve mais a parco empenho em construir propostas pedagógicas do que a uma antipatia ou discordância em relação a eles. Valem aqui todos os comentários que fizemos no item anterior.

\section{Conclusões}

Estamos conscientes de que o universo pesquisado por nós está longe de fazer justiça a tudo que se tem publicado. Não analisamos revistas não universitárias de amplo acesso aos professores, revistas de universidades do Brasil às quais não poderíamos ter acesso com o tempo de que dispúnhamos, livros e capítulos de livros, ou seja, nossa pesquisa não cobriu um número certamente importante de publicações dedicadas ao tema ética e educação. Todavia, acreditamos que nossa amostra é representativa e que, portanto, as observações que fizemos a partir dela provavelmente aplicam-se à produção brasileira dos últimos anos. Eis as principais observações:

- Embora a produção de textos sobre ética e educação tenha aumentado nos últimos anos, ela ainda é pequena, pelo menos não equivalente à preocupação atual e à demanda dos professores.

- Ética costuma ser entendida como a moral, ou seja, como campo de prescrições, de direitos e deveres, com destaque para a dignidade do ser humano e para a justiça. Às vezes ética é pensada como reflexão sobre a moral (filosófica e científica), mas quase nunca como referência às virtudes e ao sentido da vida (felicidade ou "vida boa").

- As abordagens filosófica, sociológica e psicológica são as mais lembradas; pensadores identificados com a Educação são pouco citados.

- 0 "tom" dos escritos é quase sempre crítico, seja em relação à sociedade contemporânea, seja em relação à escola atual, seja em relação a ambas. 
- Deve ser notado o pequeno número de pesquisas de campo, de dados empíricos; e, quando existem, referem-se aos campos da psicologia e da sociologia, e não da educação.

- Praticamente são inexistentes propostas educacionais de formação ética e educação moral e, coerentemente, o Documento Ética dos PCNs é pouco citado, o que leva a pensar que a proposta governamental pouca repercussão teve, pelo menos no meio acadêmico.

Não é possivel saber se a importância do tema ética e educação, que tem gerado mais publicações nos últimos anos, permanecerá presente e até aumentará, ou se voltará a cair no esquecimento. Em compensação, não parece haver muitas dúvidas a respeito da urgência desta questão, pois nada indica que os problemas atuais de anomia, desrespeito, violência e outros mais desaparecerão milagrosamente sem intervenções sociais. Uma questão central merece, a nosso ver, maiores reflexões e debate: deve, ou não, a escola comprometerse oficialmente com objetivos explícitos e programas claros, com a formação ética (ou educação moral, pouco importa a terminologia) dos alunos?

\section{Referências bibliográficas}

ARISTOTE. Éthique à Nicomaque. Paris: Flamarion, 1965.

BRASIL. Ministério da Educação e Cultura. Parâmetros Curriculares Nacionais. Brasília: Secretaria de Educação Fundamental, 1997. Ministério da Educação e Cultura. Parâmetros Curriculares Nacionais. Brasília: Secretaria de Educação Fundamental, 1998.

COMTE-SPONVILLE, A.; Ferry, J. L. La sagesse des modernes. Paris: Lafont, 1998.

DURKHEIM, E. L'education morale. [1902] Paris: PUF, 1974.

FREUD, S. Le moi et le ça. [1922] Paris: PUF, 1991.

GILLIGAN. C. Uma voz diferente. Rio de Janeiro: Rosa dos Ventos, 1982.

KANT, E. Critique de la raison pratique. [1788] Paris: PUF, 1985.

KOHLBERG, L. Essays on moral development. S. Francisco: Harper \& Row, 1981, 1984, 1987.

LÉVY-BRUHL, L. La morale et la science des moeurs. Paris: PUF, 1971.

LIPOVETSKY, G. Le crépuscule du devoir. Paris: Gallimard, 1992.

MacINTYRE, A. Après la vertu. Paris: PUF, 1997.

PIAGET, J. Le jugement moral chez l'enfant. Paris: PUF, 1932.

RICOEUR, P. Soi-même comme un autre. Paris: Seuil, 1990.

SPITZ, B. La morale à zéro. Paris: Seuil, 1995.

TAYLOR, C. Les sources du moi. Paris: Seuil, 1998.

TUGENDHAT, E. Conférences sur l"éthique. Paris: PUF, 1998.

TURIEL, E. The development of social knowledge: morality and convention. Cambridge: Cambridge University Press, 1983.

WEBER, M. Le métier et la vocation d"homme politique. [1912] Paris: Plon, 1963. 


\section{Obras analisadas}

ABICAIL, C. A. Direitos humanos e cidadania: a educação como campo de conflito. Revista Brasileira de Educação, São Paulo, n. 19, p. 138-147, jan./abr. 2002.

ADORNO, S. A socialização incompleta: os jovens delinqüentes expulsos da escola. Cadernos de Pesquisa, São Paulo, n. 79, p. 7680, nov. 1991.

ALENCAR-MURTA, H. M. de et al. 0 dever e a aspiração em crianças brasileiras. Cadernos de Pesquisa, São Paulo, n. 114, p. 153177, nov. 2001.

ANPEd. Parecer da ANPEd sobre os Parâmetros Curriculares Nacionais. Revista Brasileira de Educação, São Paulo, n. 2, p. 85-92, maio/ago. 1996.

AQUINO, J. G. A indisciplina e a escola atual. Revista da Faculdade de Educação, São Paulo, v. 24, n. 2, p. 181-204, jul./dez. 1998.

ARAÚJO, U. F. Escola, democracia e a construção de personalidades morais. Educação e Pesquisa, São Paulo, v. 26, n. 2, p. 91 107, jun./dez. 2000.

ARAÚJO, V. A. A. Cognição, afetividade e moralidade. Educação e Pesquisa, São Paulo, v. 26, n. 2, p. 137-153, jun./dez. 2000.

BELLINI, L. M.; RUIZ, A. R. Moralidade, ética, autonomia e educação. Revista Brasileira de Estudos Pedagógicos, Brasília, v. 78, n. 188/189/190, p. 216-235, jan./dez. 1997.

CUNHA, L. A. Os Parâmetros Curriculares para o ensino fundamental: convívio social e ética. Cadernos de Pesquisa, São Paulo, n. 99, p. 60-72, nov. 1996.

Sociedade, Estado e educação: notas sobre Rousseau, Bonald e Saint-Simon. Revista Brasileira de Educação, São Paulo, n. 1, p. 50-66, jan./abr. 1996.

CURY, C. R. J. Os Parâmetros Curriculares Nacionais e o ensino fundamental. Revista Brasileira de Educação, São Paulo, n. 2, p. 4-17, maio./ago. 1996.

DAVIS, C.; LUNA, S. A questão da autoridade na educação. Cadernos de Pesquisa, São Paulo, n. 76, p. 65-70, fev. 1991.

LA TAILLE, Y. de Desenvolvimento moral: a polidez segundo as crianças. Cadernos de Pesquisa, São Paulo, n. 114, p. 89-119, nov. 2001.

Para um estudo psicológico das virtudes morais. Educação e Pesquisa, São Paulo, v. 26, n. 2, p. 109-121, jun./dez. 2000.

LA TAILLE, Y. de; FLOR, C. M.; FEVORINI, L. B. A obrigatoriedade do ensino segundo alunos de 7 a 14 anos: dever hipotético e dever moral. Cadernos de Pesquisa, São Paulo, n. 28, p. 27-39, ago. 1991.

LA TAILLE, Y. de et al. Construção da fronteira da intimidade: a humilhação e a vergonha na educação moral. Cadernos de Pesquisa, São Paulo, n. 82, p. 43-55, ago. 2000.

LEITE, I. Processo educativo no mundo contemporâneo: a práxis intencional e o resgate da cidadania. DOXA-Revista Paulista de Psicologia e Educação, São Paulo, v. 4, n. 1, p. 142-158, jan./jun. 1998.

MARTINS, A. M. Autonomia e educação: a trajetória de um conceito. Cadernos de Pesquisa, São Paulo, n. 115, p. 207-232, mar. 2002.

MENIN, M. S. de S. Valores na escola. Educação e Pesquisa, São Paulo, v. 28, n. 1, p. 91-100, jan./jun. 2002.

MOGILKA, M. Autonomia e formação humana em situações pedagógicas: um difícil percurso. Educação e Pesquisa, São Paulo, v. 25, n. 2, p. 57-68, jul./dez. 1999. 
OLIVEIRA, R. J. de Ética e educação: a formação do homem no contexto de crise da razão. Revista Brasileira de Educação, São Paulo, n. 2, p. 33-41, mai./ago. 1996.

OLIVEIRA, R. J. de; CANEN, A.; FRANCO, M. Ética, multiculturalismo e educação: articulação possível? Revista Brasileira de Educação, São Paulo, n. 13, p. 113-126, jan./abr. 2000.

PALMA FILHO, J. C. Cidadania e educação. Cadernos de Pesquisa, São Paulo, n. 104, p. 101-121, jul. 1998.

RIBEIRO, M. Educação para a cidadania: questão colocada pelos movimentos sociais. Educação e Pesquisa, São Paulo, v. 28, n. 2, p. 113-128, jul./dez. 2002.

SPOSITO, M. P. Um breve balanço da pesquisa sobre violência escolar no Brasil. Educação e Pesquisa, São Paulo, v. 27, n. 1, p. 87-103, jan./jun. 2001

A instituição escolar e a violência. Cadernos de Pesquisa, São Paulo, n. 104, p. 58-75, jul. 1998.

TAVARES DOS SANTOS, J. V. A violência na escola: conflitualidade social e ações civilizatórias. Educação e Pesquisa, São Paulo, v. 27, n. 1, p. 105-122, jan./jun. 2001.

TIRIBA, L.; BARRADAS, M. S. S. Criança, meio ambiente e cidadania. Revista Brasileira de Estudos Pedagógicos, Brasília, n. 176, p. 35-50, jan./abr. 1993.

Recebido em 06.02.04

Aprovado em 14.04 .04

Yves de La Taille é professor do Instituto de Psicologia da USP, especialista em Psicologia Moral. Autor, entre outros livros, de Limites, três dimensões educacionais (Ática, 1998) e Vergonha, a ferida moral (Vozes, 2002).

Lucimara Silva de Souza é aluna do $5^{\circ}$ ano do curso de Psicologia da USP, bolsista de pesquisa sobre a generosidade na infância.

Letícia Vizioli é aluna do $5^{\circ}$ ano do curso de Psicologia da USP, bolsista de pesquisa sobre a generosidade na infância. 